\title{
Predictors of ICU Admission and Mortality in Patients with Coronavirus Disease in Community Hospitals in Virginia
}

\author{
Vikas Pathak, ${ }^{1}$ Courtney Conklin ${ }^{2}$
}

\begin{abstract}
Background Coronavirus Disease 2019 (COVID-19) is caused by novel coronavirus Severe Acute Respiratory Syndrome Coronavirus 2 (SARS-CoV-2). The mortality of patients in the Intensive Care Unit (ICU) is variable and has been reported to be as high as $80 \%$. Not much is known about the factors leading to the progression of hospitalized patients to requiring ICU care and the predictors of mortality among ICU patients. We performed univariate followed by multivariate logistic regression analysis to determine predictors of progression of the disease and factors associated with mortality.

Data and Methods Retrospective data were collected from 101 consecutive patients admitted from March, 2020 to June, 2020. Data were collected from five different community hospitals in eastern Virginia with varied demographics. Results A total of 101 consecutive hospitalized patients in five community hospitals in eastern Virginia were enrolled in the study. Out of the 101 patients, 53 were admitted into the ICU for respiratory failure. Of these 53,40 patients required intubation and mechanical ventilation. Altogether, 30 of the 53 patients admitted to the ICU died. Of these 30 patients, 25 required intubations. Of these 25 patients, one had mild, 6 moderate and 18 severe Adult Respiratory Distress Syndrome (ARDS). Patients aged 60 years and above accounted for $>2 / 3^{\text {rd }}$ of the cases in ICU.

Conclusion Patients with underlying conditions, elevated inflammatory markers, multi-organ failure and the need for mechanical ventilation were consistently associated with poor outcomes in patients with COVID-19.

Keywords COVID-19, SARS-CoV2, ICU, outcomes, mortality
\end{abstract}

\section{INTRODUCTION}

The Coronavirus Disease 2019 (COVID-19) has wreaked havoc around the globe with unprecedented morbidity and mortality, with no end in sight. The situation is particularly worse in the United States where it has infected over 20 million, killing over 349,000 people as of January $2^{\text {nd }}, 2021$ (at which point there were 84 million cases worldwide with over 1.8 million deaths). ${ }^{1}$ Since the start of the pandemic in early 2020, there has been a concerted effort by the medical community to stem the tide. There have been hundreds of research studies across the globe attempting to uncover potential variables that can be targeted; which in turn could lead to a favorable outcome in patients with COVID-19. Researchers have consistently come up with two variables -- age and the need for mechanical ventilation -- as the potential markers of mortality, which is about $16-97 \%$. $^{2-6}$

Given the high mortality rate in the ICU, particularly in patients with a combination of advanced age and the need for mechanical ventilator support, ${ }^{6}$ providers have been searching for reasons leading to ICU admission altogether ${ }^{7}$. There has been an armament of medications used early on to prevent mechanical ventilation. This includes supplemental oxygen therapy with high flow, non-invasive positive pressure ventilation, medications like dexamethasone, ${ }^{8}$ Remdesivir ${ }^{9}$ and non-medical therapies such as awake proning. ${ }^{6}$

Using logistic regression analysis, we sought to identify variables (both clinical and non-clinical) that lead to the clinical deterioration of patients admitted to the hospital with COVID-19, triggering transfer from the medical floor to the ICU and, subsequently, the factors that lead to unfavorable outcomes. Our retrospective study, involving five community hospitals in rural setting, followed the patient to either death or discharge.

\section{DATA AND METHODS}

Study Design

The study was designed as a retrospective study. It was approved by Institutional Review Board (IRB). The data were collected from patients admitted to five rural community hospitals within Riverside Health System in Eastern Virginia from March $13^{\text {th }}$ to June $30^{\text {th }} 2020$. Outcomes were re-assessed in July and again on August 22nd, 2020. Of these five hospitals, one is a regional medical center and others were community hospitals.

Data Collection

All data were collected from electronic medical records. Comprehensive data were collected which included demographics, comorbidities, presenting symptoms, numbers of days patient was admitted on the floor and in the ICU, oxygen requirements, laboratory values (admission and peak values), radiological data, treatment offered and the outcomes.

Subjects

Patients admitted to the floor, unofficially called "the COVID unit" and patients admitted to the ICU. Patients received supplemental oxygen therapy with nasal cannula, high flow oxygen and non-invasive positive pressure ventilation (NIPPV). Early in the pandemic, due to concerns for aerosolization, NIPPV was used less often but utilized more as the unfavorable outcomes were noted on mechanical ventilation. Patients also received the compassionate and FDA approved medications on the floor.

Patients in the ICU were uniformly treated with ARDS protocol (high PEEP, low FIO2, tidal volume 6-8 ml/ kg/IBW with goal plateau pressure of $<30 \mathrm{cmH} 2 \mathrm{O}$ ). ARDS severity was classified into mild, moderate and severe disease based on Berlin classification. ${ }^{10}$ Other than mechanical ventilation 
and supplemental oxygen, treatments offered included Hydroxychloroquine, Tocilizumab, convalescent plasma, Remdesivir and corticosteroids. The treatment was based on treating physician's discretion. Similarly, corticosteroid and antibiotic use was dictated by the intensivist. The patients also received inhaled nitric oxide, deep sedation (Richmond Agitation Sedation Scale goal of -4), prone positioning and paralytics to achieve the goal $\mathrm{PaO} 2$ of 55 $\mathrm{mmHg}$. Prone positioning was used for 16 hours at a time and repeated after an 8-hour break if needed.

\section{Statistical Analysis}

The Mann-Whitney U-test and Chi-squared test were used to compare differences between the two groups. A $p$-value of $<0.05$ was considered statistically significant. Measures of central tendencies like mean and median were used as well to describe descriptive data. Univariate and multivariate logistic regression analysis of factors leading to ICU admission (from the COVID unit) and mortality in the ICU were performed.

\section{RESULTS}

Total of 101 patients from five different community hospitals were enrolled in the study, of which $53(52 \%)$ were treated in the medical ICU (figure 1). Of the $53 \mathrm{ICU}$ patients, $47 \%$ were male and $53 \%$ were females. A total of $49 \%$ of the patients were Caucasian and $51 \%$ African American. About $1 / 3^{\text {rd }}(34 \%)$ of patients admitted to the ICU were between the ages $70-79$ years, while $1 / 4^{\text {th }}(26 \%)$ were between $60-69$ years. In total, $74 \%$ of patients were $>60$ years of age. Comorbidity wise, hypertension $(83 \%)$, diabetes mellitus (55\%), obesity (57\%) and COPD/asthma $(30 \%)$ were most common. About $49 \%$ of the patients were current or former smokers.

Shortness of breath and cough were the most common presenting symptoms $(>80 \%)$. Blood work showed white blood cell count and platelet count both peaked on day 8. While C-reactive protein (CRP), D-dimer and ferritin peaked on day 8,7 and 6 respectively. Of the 53 patients in the ICU, $40(75 \%)$ were intubated and 13 patients $(25 \%)$ were not intubated.

Of the 53 patients in the ICU, 30 patients died (57\%). Of these 30 patients, 12 were male and 18 were female. Total 15 Caucasian and 15 were African Americans. About $78 \%$ of these patients were age 60 years and above. Hypertension, obesity, diabetes mellitus and asthma/COPD accounted for the most common comorbidities. Of these 53 patients, one had mild ARDS ( $\mathrm{PaO} 2 / \mathrm{FiO} 2$ ratio 200-300 $\mathrm{mmHg}$ ), 12 had moderate ARDS (PaO2/FiO2 ratio $100-200 \mathrm{mmHg}$ ) and 27 patients had severe ARDS ( $\mathrm{PaO} 2 / \mathrm{FiO} 2$ ratio $<100 \mathrm{mmHg})$. A total of 7 out of the 53 patients admitted to the ICU (22\%) did not have ARDS. The average length of stay in the ICU was 8 days with an average of 6 days on the ventilator.

Of the 53 that were admitted to the ICU, $8(15 \%)$ patients received Remdesivir, 8 (15\%) received Tocilizumab, and 2 (4\%) received convalescent plasma. Hydroxychloroquine was administered in 27 of the $53(51 \%)$ patients, 40 of the $53(75 \%)$ received Azithromycin and 31 of the $53(58 \%)$ received corticosteroids (hydrocortisone, dexamethasone, and methyl-prednisone); corticosteroids were used for various reasons (underlying airway disease, hypotension) and for variable days. All patients received deep venous thrombosis prophylaxis and broad-spectrum antibiotics.
Figure 1: Flow chart showing distribution of the patients
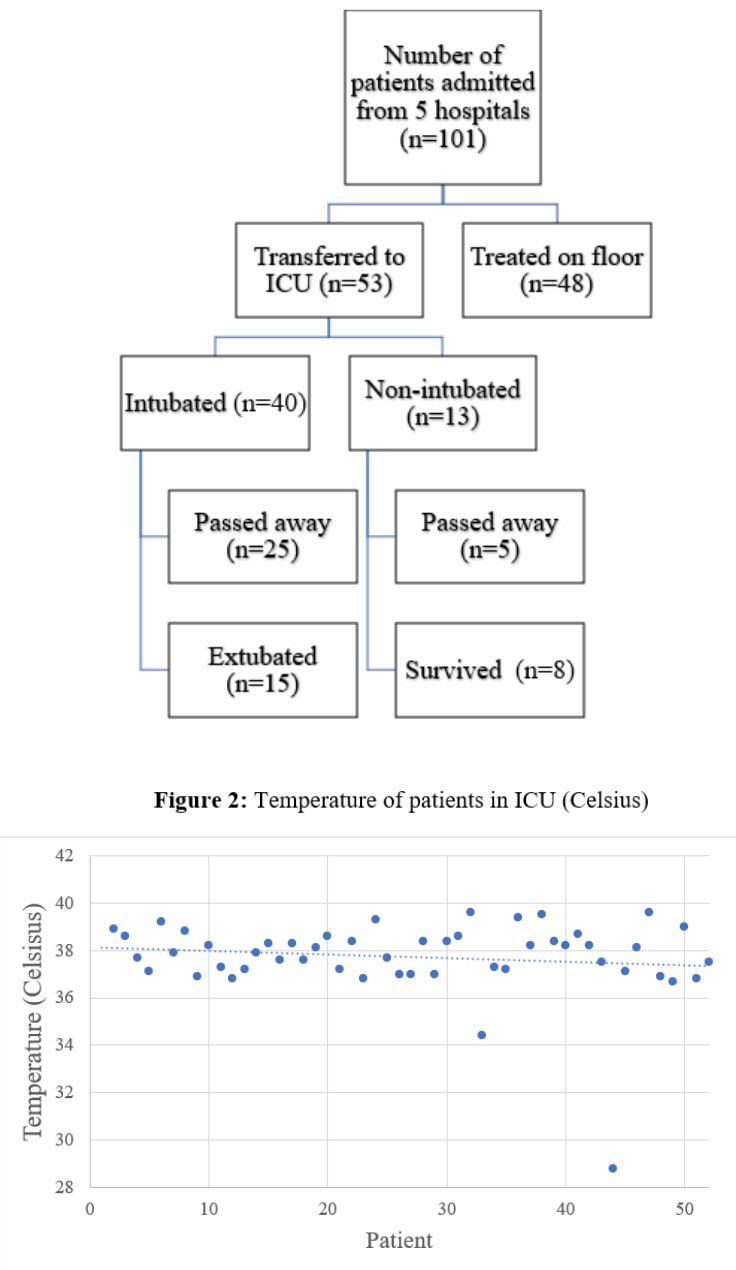

Of the 30 patients who died in the ICU, 25 patients were intubated and mechanically ventilated. A total of $11 / 25(44 \%)$ patients passed away while on mechanical ventilation and $11 / 25(44 \%)$ had compassionate extubation. Of the non-intubated patients, 4 patients who passed away had Do Not Intubate (DNI) orders and one was on NIPPV. Of these 30 patients, one had mild, 6 had moderate and 18 had severe ARDS. The inflammatory marker peaks were similar in these group (survivor and non-survivor). Of these 30 patients, 10 had superinfection with bacteria and 2 had an additional non-coronavirus viral infection.

Venous thromboembolism was diagnosed in 5/30 $(17 \%)$ patients, acute kidney injury was noted in $21 / 30$ $(70 \%)$ patients, of which $8 / 21(38 \%)$ required hemodialysis. Vasopressors were used in $21 / 30(70 \%)$ patients. Overall mortality in ICU was $57 \%$ (30/53 patients). The mortality for those who required mechanical ventilation was $63 \%$ $(25 / 40)$

\section{Logistic Regression}

Demographics including age, body mass index (BMI), and race were not predictive of ICU admission or worse outcome (Table 1). From comorbidities standpoint, diabetes mellitus and hypertension were two predictors of progression to ICU admission, while chronic kidney disease, congestive 
Table 1: Logistic regression results showing factors associated with poor outcomes

\begin{tabular}{|c|c|c|c|c|c|}
\hline Category & $\begin{array}{c}\text { Total of all } \\
\text { patients (101) }\end{array}$ & $\begin{array}{l}\text { Total of ICU } \\
\text { patients (53) }\end{array}$ & $\begin{array}{r}P \text {-value } \\
\text { for ICU } \\
\text { admission }\end{array}$ & $\begin{array}{r}\text { Total of Expired } \\
\text { (32) }\end{array}$ & $\begin{array}{r}P \text {-value } \\
\text { for overall } \\
\text { outcome }\end{array}$ \\
\hline \multicolumn{6}{|l|}{ Comorbidity } \\
\hline Diabetes mellitus & 43 & 29 & 0.01 & 16 & 0.30 \\
\hline Hypertension & 75 & 44 & 0.038 & 28 & 0.04 \\
\hline Chronic kidney disease & 17 & 11 & 0.27 & 10 & 0.01 \\
\hline Congestive heart failure & 15 & 11 & 0.10 & 09 & 0.01 \\
\hline Malignancy & 16 & 11 & 0.16 & 09 & 0.02 \\
\hline \multicolumn{6}{|l|}{ Admission labs } \\
\hline Creatinine (average, mg/dl) & 1.45 & 1.81 & 0.01 & 1.87 & 0.03 \\
\hline C-reactive protein (average, mg/dl) & 142 & 165 & 1.0 & 181 & 0.03 \\
\hline Peak labs & \multicolumn{3}{|c|}{ Average of Expired Patients (32) } & \multicolumn{2}{|c|}{$\begin{array}{r}P \text {-value for overall } \\
\text { outcome }\end{array}$} \\
\hline White blood count & \multicolumn{3}{|c|}{16.8} & \multicolumn{2}{|r|}{0.0001} \\
\hline Creatinine & \multicolumn{3}{|c|}{3.42} & \multicolumn{2}{|r|}{0.009} \\
\hline CRP & \multicolumn{3}{|c|}{274} & \multicolumn{2}{|r|}{0.0002} \\
\hline AST & \multicolumn{3}{|c|}{612} & \multicolumn{2}{|r|}{0.01} \\
\hline D-dimer & \multicolumn{3}{|c|}{16.5} & \multicolumn{2}{|r|}{0.003} \\
\hline Ferritin & \multicolumn{3}{|c|}{2434} & \multicolumn{2}{|r|}{0.02} \\
\hline \multicolumn{6}{|l|}{ ICU } \\
\hline Days in ICU (average) & \multicolumn{3}{|c|}{8} & \multicolumn{2}{|r|}{0.03} \\
\hline Days on ventilator (average) & \multicolumn{3}{|c|}{6} & \multicolumn{2}{|r|}{0.02} \\
\hline \multicolumn{2}{|c|}{$\begin{array}{l}\text { Mechanical ventilation (number of patients/total expired } \\
\text { patients) }\end{array}$} & \multicolumn{2}{|l|}{$25 / 32$} & \multicolumn{2}{|r|}{0.00001} \\
\hline ARDS & \multicolumn{3}{|c|}{$25 / 32$} & \multicolumn{2}{|r|}{0.00001} \\
\hline Bacterial infection & \multicolumn{3}{|c|}{$11 / 32$} & \multicolumn{2}{|r|}{0.01} \\
\hline Acute kidney injury & \multicolumn{3}{|c|}{$22 / 32$} & \multicolumn{2}{|r|}{0.0001} \\
\hline Need for hemodialysis & \multicolumn{3}{|c|}{$8 / 32$} & \multicolumn{2}{|r|}{0.019} \\
\hline Vasopressor requirement & \multicolumn{3}{|c|}{$21 / 32$} & & 0.0001 \\
\hline
\end{tabular}

heart failure, underlying malignancy and hypertension were predictive of unfavorable outcomes.

Patients' presenting symptoms did not predict poor outcomes, however myalgias, altered mental status and fever were strongly protective and predictors of good outcomes. Elevated creatinine upon admission predicted progression of the overall disease, while increase in creatinine and CRP both predicted worse outcomes. Peak in WBC count, creatinine, CRP, AST, D-dimer and Ferritin led to unfavorable outcomes. Elevated admission and peak platelet counts were associated with good outcome. Radiological findings of ground glass opacities also leaned towards unfavorable outcome.

Once the patient was admitted to the ICU, the number of days in the ICU, intubation, number of days on mechanical ventilation, diagnosis of ARDS, bacterial superinfection, acute renal failure, need for hemodialysis and vasopressor requirement all led to poor outcome.

\section{DISCUSSION}

Our study found that patient with diabetes mellitus and hypertension along with elevated creatinine and CRP on admission were predictors of clinical deterioration leading to ICU admission. We also found that patients in the ICU with continued elevated inflammatory markers like CRP, D-dimer and ferritin had poor outcomes. Similarly, continued elevation of WBC and AST was associated with poor outcome. Renal failure and the need for dialysis was universally related to unfavorable outcomes. Congestive heart failure, chronic kidney disease and malignancy were not associated with ICU admission, but did predict unfavorable outcome. We also found that in the ICU, the need for mechanical ventilation, diagnosis of ARDS, renal failure and need for vasopressors were independently related to higher mortality.

We also noted that the presenting symptoms of myalgia, altered mental status and fever (figure 2) were protective. Elevated platelet counts were found to be protective as well. Our study has the advantage of using the demographics from a large geographical area, including 5 different community hospitals. We also had the advantage of following the patient to a definite endpoint (death or hospital discharge). 
Table 2: Age and outcomes

\begin{tabular}{|lrrr|}
\hline \multicolumn{4}{|c|}{ Table 2: Age and outcomes } \\
\hline Age (years) & Deceased & Survived & Total \\
\hline$<40$ & 02 & 01 & 03 \\
$40-49$ & 03 & 01 & 04 \\
$50-59$ & 02 & 05 & 07 \\
$60-69$ & 05 & 08 & 13 \\
70 and above & 20 & 05 & 25 \\
Total & 32 & 20 & 52 \\
Mann Whitney U-test, $p=0.83$ & & \\
\hline
\end{tabular}

King et al. ${ }^{6}$ had shown advanced age as the risk factor for mortality. However, in our study although the patients with advanced disease were more likely to have unfavorable outcome (RR 1.1, OR 1.65 with 95\% CI), statistically it was not significant (Mann Whitney $U$ test, $p=0.08$ ), logistic regression did not show age as the predictor of mortality either (table 2). It is likely that patients with advanced age due to respiratory distress were more prone to mechanical ventilation and ARDS which indirectly increases the mortality. King et al. ${ }^{6}$ is the only other recent study that followed the patients to the end point (discharge or death) while looking at the outcomes of mechanically ventilated patients with COVID-19 related respiratory failure. They had 164 patients in the ICU that required mechanical ventilation, 70/164 (43\%) died. In their study, deceased patients were older (age >70) and had a higher initial D-dimer and peak ferritin levels compared to survivors. Compared to study by King et al., the mortality rate in our ICU was $57 \%$, and similar to their study elevated D-dimer and Ferritin showed unfavorable outcome; although we also noted CRP as the marker of clinical deterioration and mortality.

Richardson et $\mathrm{al}^{2}{ }^{2}$ included the data from Northwell Health System, New York. They had 1151 patients who needed mechanical ventilation, however only 320 patients met the endpoint (discharge or death) of which 282 patients died (88\%). Rest were still in the hospital. Zhou et al. ${ }^{3}$ reported $97 \%$ mortality (31/32 patients requiring mechanical ventilation died).

Our study has several limitations that we acknowledge, including retrospective data and small sample study. Also, the sample is from March to June, 2020 during which there were many uncertainties of the treatment of these patients. Majority of our patients received Hydroxychloroquine and Azithromycin but only few received Remdesivir (compassionate use). Lack of FDA approved treatments at that time, lack of research on medicines in the community hospital, and lack of Extracorporeal Membrane Oxygenation (ECMO) did not allow us to perform logistic regression analysis on the medical treatment.

\section{CONCLUSION}

Patients with underlying conditions, elevated inflammatory markers, multi-organ failure and the need for mechanical ventilation were consistently associated with poor outcomes in patients with COVID-19.

\section{REFERENCES}

1. Johns Hopkins University, Coronavirus Resource Center.
Last accessed January $2^{\text {nd }}, 2021$. Coronavirus.jhu.edu.

2. Richardson S, Hirsch JS, Narasimhan M, et al. Presenting Characteristics, Comorbidities, and Outcomes Among 5700 Patients Hospitalized With COVID-19 in the New York City Area [published correction appears in JAMA. 2020 May 26;323(20):2098]. JAMA. 2020;323(20):2052-2059. doi:10.1001/ jama.2020.6775

3. Zhou F, Yu T, Du R, et al. Clinical course and risk factors for mortality of adult inpatients with COVID-19 in Wuhan, China: a retrospective cohort study [published correction appears in Lancet. 2020 Mar 28;395(10229):1038] [published correction appears in Lancet. $2020 \mathrm{Mar}$ 28;395(10229):1038]. Lancet. 2020;395(10229):1054-1062. doi:10.1016/S0140-6736(20)30566-3

4. Bhatraju PK, Ghassemieh BJ, Nichols M, et al. Covid-19 in Critically Ill Patients in the Seattle Region - Case Series. N Engl J Med. 2020;382(21):2012-22. doi:10.1056/ NEJMoa2004500

5. Grasselli G, Zangrillo A, Zanella A, et al. Baseline Characteristics and Outcomes of 1591 Patients Infected With SARS-CoV-2 Admitted to ICUs of the Lombardy Region, Italy. JAMA. 2020;323(16):1574-1581. doi:10.1001/ jama.2020.5394

6. King CS, Sahjwani D, Brown AW, Feroz S, Cameron P, Osborn E, Desai M, Djurkovic S, Kasarabada A, Hinerman R, Lantry J, Shlobin OA, Ahmad K, Khangoora V, Aryal S, Collins AC, Speir A, Nathan S. Outcomes of mechanically ventilated patients with COVID-19 associated respiratory failure. PLoS One. 2020 Nov 23;15(11):e0242651. doi: 10.1371/journal.pone.0242651. PMID: 33227024; PMCID: PMC7682899.

7. Scaravilli V, Grasselli G, Castagna L, et al. Prone positioning improves oxygenation in spontaneously breathing nonintubated patients with hypoxemic acute respiratory failure: A retrospective study. J Crit Care. 2015;30(6):13901394. doi:10.1016/j.jcrc.2015.07.008

8. RECOVERY Collaborative Group, Horby P, Lim WS, et al. Dexamethasone in Hospitalized Patients with Covid-19 Preliminary Report [published online ahead of print, 2020 Jul 17]. N Engl J Med. 2020; NEJMoa2021436. doi:10.1056/ NEJMoa2021436

9. Beigel JH, Tomashek KM, Dodd LE, et al. Remdesivir for the Treatment of Covid-19 - Final Report. N Engl J Med. 2020;383(19):1813-1826. doi:10.1056/NEJMoa2007764

10. ARDS Definition Task Force, Ranieri VM, Rubenfeld GD, et al. Acute respiratory distress syndrome: the Berlin Definition. JAMA. 2012;307(23):2526-2533. doi:10.1001/ jama.2012.5669

Corresponding Author Vikas Pathak, MD; Email: drvikaspathak@ gmail.com; ORCID ID: 0000-0002-7482-5908

Authors' Affiliations ${ }^{1}$ Department of Pulmonary and Critical Care, Riverside Health System, Newport News, Virginia.

${ }^{2}$ Department of Family Medicine, Riverside Health System, Newport News, Virginia.

Authors' Contributions VP - research idea, data analysis and manuscript preparation; CC - data collection and data analysis Ethical Approval This study was approved by the Institutional Review Board of the Riverside Health Systems, Newsport News, Virginia.

Conflict of Interests None declared by the authors.

Funding No external funding was received for the study Availability of Data Available upon request. The dataset is archived by the authors, as per the Institutional Review Board 
policies.

Responsible Editor Shyam Thapa, PhD

Copyrights \& Licensing (C) 2022 by author(s). This is an Open Access article distributed under the terms and condition of Creative Commons Attribution License (CC BY 4.0)

[https://creativecommons.org/licenses/by/4.0/] which permits unrestricted use, sharing, adaptation, distribution and reproduction in any medium or format, as long as you give appropriate credit to the original author(s) and the source. The images or other third party material in this article are included in the article's Creative Commons licence, unless indicated otherwise in a credit line to the material.

Disclaimer All the statements, opinions, claims, and data expressed in this publication are solely those of the author(s), and do not necessarily represent neither of their affiliated organizations, nor the publisher, the editors and the reviewers. The EJMS remains neutral with regards to any jurisdictional claims in any published articles, their contents, and the institutional affiliations of the authors. Neither the publisher, nor the editor, and reviewers are responsible for errors in the contents nor any consequences arising from the use of the information contained in it.

Timeline Received: 14 September 2021, Revised: 10 January 2022 Accepted: 28 January 2022, Published online: 1 March 2022

\section{Cite this article as:}

Pathak V, Conklin C. Predictors of ICU admission and mortality in patients with coronavirus disease in community hospials in Virginia. Europasian J Med Sci. 2021; 4(1):2-6 https://doi.org/10.46405/ejms.v4i1.386

\section{Submit your next manuscript to Europasian Journal of Medical Sciences (EJMS)}

\section{Advantage of Submission to EJMS:}

- Convenient online submission via OJS plateform

- Thorough but timely peer review

- No space constraints or color figure charges

- Online First Strategy to facilitate immediate publication online upon acceptance

- Fully open access with no embargo period

- Inclusion in Google Scholar, Crossref, Index Copernicus, NepMed and NepJol.

To submit your manuscript online, register to the website of the EJMS at this link: www.europasianjournals.com 